Environment Conservation Journal 15(1 \& 2) 21-33, 2014

ISSN 0972-3099 (Print) 2278-5124 (Online)

Abstracted and Indexed

\title{
Occupancy estimation and modeling in monitoring tigers with implications for conservation and management
}

\author{
Debabrata Swain $^{1} \bowtie$ and Paul J. Morris $^{2}$
}

Received: 05.08.2013

Accepted:10.10.2013

\begin{abstract}
The tiger (Panthera tigris) is highly endangered through out its range and one of the impediments to effective tiger conservation is the lack of simple and cost effective methods for monitoring of wild tiger populations. With an aim to find a rapid, cost effective, and statistically robust methodology to take quick management decisions, observations of tiger and co-predator sign in administrative subunits (beats) of the Similipal Tiger Reserve, located between $20^{\circ} \mathbf{2 8}^{\prime}$ and $22^{\circ} 08^{\prime}$ North latitude, and $86^{\circ} \mathrm{04}$ ' and $86^{\circ} 37^{\prime}$ 'East longitude in India, were subjected to an occupancy estimation and modeling analysis. Several environmental factors were identified as covariates with explanatory power for the pattern of observations of tiger sign. Most important of these were the proportion of the area of the beat that is classified as disturbed habitat, the distance between the beat and the nearest inhabited place, and the total number of prey observed in the beat in a separate set of surveys for ungulates and other tiger prey species. The results of this analysis have clear management implications for the reserve, with beats classifiable into four categories, each with its own target strategy for increasing tiger abundance. These categories are: highest concern, reduce disturbance, increase prey protection, and maintain current protection. This study suggests that occupancy estimation and modeling from surveys of large mammalian predator sign is a simple cost-effective statistically robust methodology that can be performed by the management staff of a reserve and can be used to engage members of the local population in conservation.
\end{abstract}

Keywords: conservation management, occupancy analysis, Panthera tigris, Tiger conservation

\section{Introduction}

The tiger (Panthera tigris Linnaeus 1758) is highly endangered throughout its range with five remaining highly endangered subspecies Panthera tigris tigris Linnaeus 1758 in India, Bhutan, Nepal, Bangladesh, western Myanmar, and south-western China, Panthera tigris corbetti Mazak 1968, in eastern Myanmar, south-eastern China, Malaysia, Laos, Thailand, Cambodia, and Vietnam, Panthera tigris amoyensis Hilzheimer 1905 in South China, Panthera tigris sumatrae Pocock 1929 in Sumatra, and Panthera tigris altaica Temminck 1844 in north-eastern China, North Korea and Far Eastern Russia. Tiger populations have been extirpated from Afghanistan, Turkmenistan, Iran, Turkey, Java, and Bali with the extinction of three subspecies, the Caspian tiger Panthera tigris virgata Illiger 1815, the Javan tiger Panthera tigris sondaica Temminck 1844, in north-eastern China, North Korea and Far Eastern Russia. Tiger

\footnotetext{
Author's Address

${ }^{1}$ Aranya Bhawan, Chandrasekharpur, Bhubaneswar, Odisha, India.

${ }^{2}$ Harvard University Herbaria and Museum of Comparative Zoology, 22 Divinity Ave, Cambridge MA 02138, USA.

Email: debabrataswain@yahoo.co.in
}

populations have been extirpated from Afghanistan, Turkmenistan, Iran, Turkey, Java, and Bali with the extinction of three subspecies, the Caspian tiger Panthera tigris virgata Illiger 1815, the Javan tiger Panthera tigris sondaica Temminck 1844, and the Bali tiger Panthera tigris balica Schwarz 1912 (Maza'k, 1996; Nowell and Jackson, 1996; Kitchener, 1999; Seidensticker et al., 1999; Sunquiste, et al., 1999; Dinerstein et al., 2007). The primary causes of disappearance of tigers are poaching, habitat loss and degradation, prey depletion, and conflict with humans (Nowell and Jackson, 1996; Ramakrishnan et al., 1999; Seidensticker et al., 1999; Johnsingh and Negi, 2003; Graham et al., 2005; Wang and Macdonald, 2006; Ranganathan et al., 2008). One of the impediments to effective conservation is the lack of simple and cost effective monitoring of wild tiger populations. Nichols and Karanth (2002) define monitoring of animal populations as the estimation of absolute or relative abundance for the purpose of drawing inferences about variation in abundance of animals over space and/or time. Karanth et al. (2002) mention three considerations for the 
scientific monitoring of tiger and prey populations. They are the need to objectively evaluate the success or failure of management interventions, so as to react adaptively and solve problems, to establish benchmark data that can serve as the basis for future management, and to develop a body of empirical and theoretical knowledge that can potentially improve our predictive capacity to deal with new situations. Monitoring is, therefore, tied closely to management decisions (e.g., Nichols, 1991). Tigers are cryptic and elusive animals. The dense tropical forest vegetation of their habitats coupled with highly undulating landscapes hampers the sighting, trapping and radio tracking of tigers. Non-detection of a species at a site does not imply that the species is absent unless the sensor is so effective that it has a probability of detection of one. The characteristics of tigers and their habitats make the probability of detection of tigers in the wild by any sensor substantially less than one. MacKenzie et al. $(2002,2006)$ proposed a model and likelihood-based method for estimating site occupancy rates when detection probabilities are less than one. This method provides a flexible framework enabling covariate information to be included and allowing for missing observations. Their method provides good estimates of occupancy rates, and are generally unbiased for moderate detection probabilities (ie. $>0.3$ ).

In this study, we apply this occupancy estimation and modeling approach to observations of tigers and environmental covariates in Similipal tiger reserve, Orissa, India. We selected Similipal because it is the fourth largest tiger reserve in India with modest population of tiger and leopard; the traditional pugmark census (Singh, 1999) conducted in the reserve since 1972 was not statistically robust and heavily criticized (Karanth et al., 2003); it is difficult to apply any other effective methodology in dense vegetation and undulating terrain of Similipal; and one of us (D.S.) has thorough knowledge of the reserve being its director from 2002 to 2007.

\section{Materials and Method}

We adopted methods with the following objectives: First, what are the conservation implications of the application of occupancy estimation and modeling of MacKenzie et al. (2006) to a tiger reserve?
Second, is occupancy estimation and modeling a rapid and statistically robust methodology that can be performed by the management staff of a reserve to make rapid and targeted management decisions? Study Area.

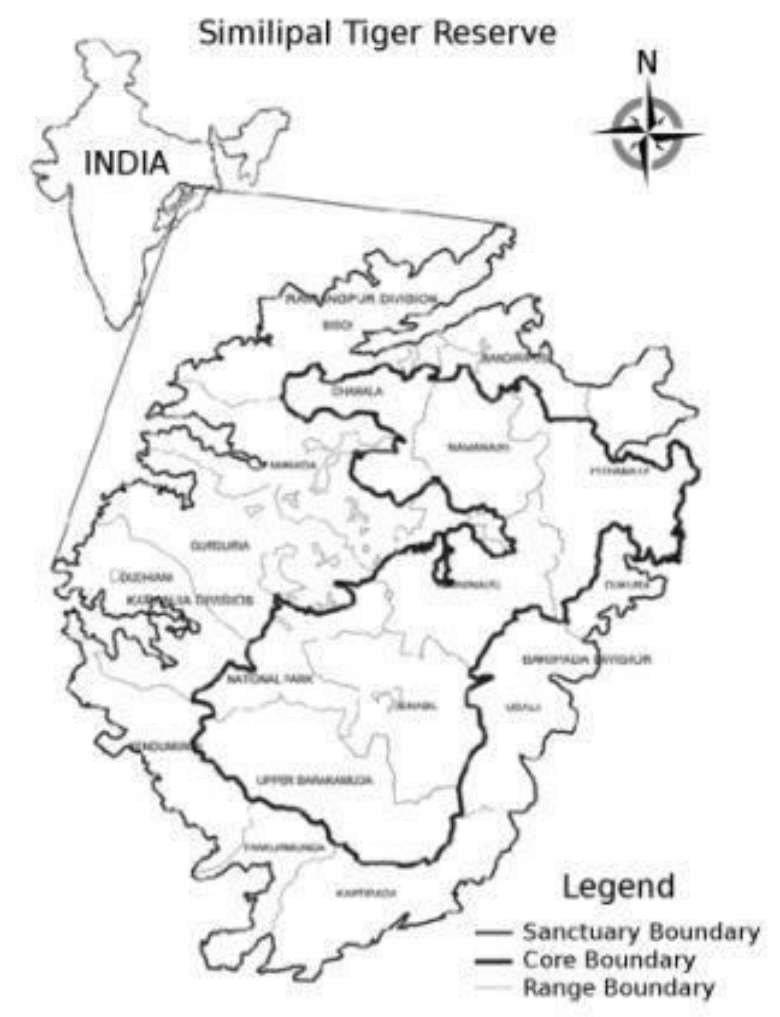

\section{Figure 1: Similipal Tiger Reserve, India}

The Similipal massif is located between $20^{\circ} 28^{\prime}$ and $22^{\circ} 08^{\prime}$ North latitude, and $86^{\circ} 04^{\prime}$ and $86^{\circ} 37^{\prime}$ East longitude in the Mayurbhanj district, Odisha (Figure 1). The hills, covering an extensive area of $2750 \mathrm{~km}^{2}$, have a large number of crests and radiating perennial streams. The elevation of the massif varies between $500 \mathrm{~m}$ and $600 \mathrm{~m}$ with outer areas 1000-1100 $\mathrm{m}$ above the mean sea level. Similipal is covered with a rich canopy of largely tropical moist deciduous forest, and harbours a rich flora and fauna of 1124 plant species (including 64 species of cultivated plants and 93 species of orchids), 41 species of mammals, 264 species of birds, 37 species of reptiles and 12 species of amphibians (Swain, 2005). Important mammalian species include tiger (Panthera tigris), leopard (Panthera pardus fusca Meyer 1794), dhole or wild $\operatorname{dog}$ (Cuon alpinus alpinus Pallas1811), leopard cat 
(Prionailurus bengalensis bengalensis Kerr 1792), jungle cat (Felis chaus kutas Pearson 1832), hyena (Hyaena hyaena Linnaeus 1758), wolf (Canis lupus pallipes Sykes 1831), Indian jackal (Canis aureus indicus Hodgson 1833), sloth bear (Melursus ursinus ursinus Shaw 1791), elephant (Elephas maximus indicus Cuvier 1798), Indian bison (Bos frontalis gaurus H.Smith 1827), sambar (Rusa unicolor Kerr 1792), chital (Axis axis Erxleben 1777), barking deer (Muntiacus muntjak aureus C. H. Smith 1826), mouse-deer (Moschiola meminna Erxleben 1777), four-horned antelope (Tetracerus quadricornis de Blainville 1816), langur (Semnopithecus entellus Dufresne 1797), and wild pig (Sus scrofa cristatus Wagner 1839). We have followed the taxonomic affiliation of Wilson and Reeder, 2005 for scientific names of mammalian species. In this region, the year can be divided into three principal seasons (Table 1) : (1) Warm, wet season (July-October); (2) Cool dry season (November-February); (3) Hot, humid season (March-June). During the warm wet season, food is abundant for animals, but rains affect their activity. There are nine meteorological stations in Similipal tiger reserve - seven inside and two just outside. Temperature, both minimum and maximum, precipitation and humidity are manually recorded every day. During the cool dry season morning frost and heavy dew are common. Foraging activity of diurnal animals begins late. During the hot humid season, the day length increases and morning temperature is higher and foraging activities start early and continue intermittently throughout the day.The Similipal tiger reserve has a well demarcated core area of $846 \mathrm{~km}^{2}$ and a buffer zone of $1904 \mathrm{~km}^{2}$ (Swain, 2005). The core area is composed of seven forest ranges: Upper Barakamuda, Chahala, Jenabil, Nawana (South), Nawana (North), Pithabata, and National Park, while the buffer zone consists of twelve forest ranges under three forest divisions: Baripada, Karanjia and Rairangpur. There are four villages with an aggregate population of approximately 450 in the core area, and 58 villages with an aggregate population of approximately 12,000 in the buffer zone. The surrounding transition zone of $10 \mathrm{~km}$ from the boundary of the reserve is densely populated, with a population of about 450,000 (2001 census).

\section{Sampling Protocol}

Beat, the smallest administrative unit of the reserve, was chosen as a sampling unit. There are 139 beats covering an area of $2210.75 \mathrm{~km}^{2}$. The average size of a beat is $15.90 \mathrm{~km}^{2}$ with the smallest and largest beats at $6.80 \mathrm{~km}^{2}$ and $49.61 \mathrm{~km}^{2}$ respectively. Of the 139 beats in the reserve, 75 are in the core area of the reserve and 64 in the buffer area. Beats were sampled as part of the All India tiger and copredator monitoring programme, and the protocol described below was developed for that programme (Jhala et al., 2005). In each beat, three individuals local to the area walked three different transects of about $5 \mathrm{~km}$ each, one on each of three consecutive days in January (2006 Jan 18-20). The behavior of tigers, and thus their resultant sign varies substantially over three different seasons of the reserve mentioned above. The cool dry season is the most favorable for the formation, preservation, and detection of tiger sign, as tigers actively travel open paths during this season, leaving detectable scrape marks, scat, and kills, and leaving tracks in the moist sediments of natural track traps.

The sampling team counted the number of signs of carnivores (tracks, scrape marks, kills, and scat) that they saw on each transect. Since tigers and leopards have a tendency to use dirt roads, trails, foot paths, river beds and nullahas, these landscape features within the beat were targeted. Three persons, one beat forest guard and two local residents, surveyed for tiger and other carnivore signs in each beat, with different local residents comprising the sampling team in each beat. The forest guard was the guard for that beat and highly familiar with both the area and the signs of animals living in that area, including training on scat and sign identification. The GPS coordinate of the beginning point of each search path was recorded. Each search path can be thought of as a winding, non-linear, transect through a portion of the beat. Each sampling team was told that the total minimum distance to be covered in the three days in each beat while searching for tiger and other carnivore sign was $15 \mathrm{~km}$ (with each transect being 4 to $6 \mathrm{~km}$ ). Tiger and leopard signs were classified into: (1) Pugmark trails, (2) Scats, (3) Scrapes, (4) Scent marks (spray, rolling), (5) Rake marks on trunks, (6) Actual sighting, (7) Roaring (vocalization), (8) Kills (Predation on wild prey). Record was also kept for signs of any other 
carnivore that were encountered. The other carnivore species recorded were wild dog, bear, hyena, wolf and jackal. A separate transect of $2 \mathrm{~km}$ each in a beat was walked on three subsequent mornings (2006 January 21-23), and on these the survey teams recorded the numbers of mammals (primarily ungulates) they saw. After considering the shape, size, vegetation, and terrain type of the beat, a transect line of $2 \mathrm{~km}$ was marked for sampling. Care was taken that a line transect was not located near a busy road nor run parallel to a river or other features of the landscape that could bias sighting of ungulates. The GPS coordinates of the beginning and end points were recorded for each transect. Each transect was walked by three persons during the early morning hours (6:30 AM to 8:30 AM). Preferably one of the persons walking was a good field person who was able to spot wildlife. Each line transect was walked on three different mornings for estimating ungulate encounter rates.

\section{Sign Detection Training}

Intensive training was conducted for the master trainers (Assistant Conservator of Forests and Range Officers) who also acted as supervisors in the monitoring process. The master trainers imparted training including practical demonstration to beat forest guards in the Range level. One day prior to the beginning of monitoring programme a mock exercise was conducted in each beat. Therefore the Beat forest guards, who are the leaders of each sampling unit, had received training of about 16 hours to identify animals, animal signs and recording of data on data sheets. They were provided booklets detailing procedures and identification cards for animals and animal signs. Forest guards of the reserve are also highly skilled at identifying carnivore scats and signs. One of us (D.S.), as director of the reserve, personally supervised the training and implementation of the monitoring protocol.

\section{Classification of Beats and Site Covariates}

For analysis of the observational data, we classified land use and measured distance from beat edge (forest) to villages/inhabited areas. For land use classification, the satellite data utilised were of IRS-1D, sensor LISS-III, spatial resolution $23.5 \mathrm{~m} * 23.5 \mathrm{~m}$ and spectral resolution 4 bands and the classification was procured from Orissa Space Application Centre, Bhubaneswar, India. In this classification, dense forest is forest canopy cover more than $40 \%$, open forest is canopy cover between $10 \%$ and $40 \%$, and degraded forest is the canopy cover less than $10 \%$. Distance from habitation was expressed as the distance from the edge of the beat to the edge of the nearest inhabited place in $\mathrm{km}$. Potential site covariates examined in this study and the codes used for them in this paper are listed in Table 2.

\section{Data analysis}

A data set consisting of binary observed presence of tiger sign on each of three replicate samplings of a beat, and a set of site covariates was analysed with the software package PRESENCE Version 2.2 (Hines, 2006) (numeric results reported here using build <090330.1129> running under wine on a Debian Linux system were consistent with data exploration using 100 bootstrap iterations on a Windows XP system). All analyses reported here used bootstrap analysis with 2000 iterations.

The AIC (Akaike Information Criterion) is a measure of how well a model (a combination of parameters) explains the data, with a penalty added for more parameters. Its purpose is to find the most parsimonious combinations of parameters that explain the data. The model with the smallest AIC value is viewed as the best and simplest explanation of the data. The difference between AIC values ( $\triangle \mathrm{AIC}$ ) between this minimum AIC and other models allows identification of models that also provide good and parsimonious explanations of the data. Following Burnham and Anderson (2002, p446) rule of thumb, we have tagged the models with a $\triangle \mathrm{AIC}$ of less than 2 as having substantial support, and those with $\triangle \mathrm{AIC}$ values from about 2 to 7 as having some support, and those with $\triangle \mathrm{AIC}$ values larger than 10 as poorly explaining the data. Site covariates were normalized (this does not affect the ranking of models, and only slightly affects the numeric results, for example, AIC for a model of $\Psi$ (proportion degraded habitat, distance from habitation, total prey) was 433.53 for normalized covariates, and 433.56 for raw covariates).

\section{Results and Dicussion \\ Summary of the Data}

Figure 2 shows the relationship between each of six potential covariates for tiger occupancy and the 
number of surveys in each beat in which tiger sign was observed. Of the potential covariates, the proportion of the beat that consists of degraded habitat, the proportion of the beat that consists as dense forest, the distance of the beat from human habitation, and the total number of prey (Sambar, Cheetal, Wild Pig, and Barking Deer, all known to be tiger prey in Similipal, and fitting the typical pattern of terrestrial prey half or more the large body weight of large felid carnivores, Gittleman, 1985) observed in the ungulate surveys all show patterns suggestive of a relationship with tiger presence.

Table 1: Temperature and precipitation for seasons in Simpal tiger reserve, India, 1994 to 2008.

\begin{tabular}{|l|c|c|c|}
\hline & Warm, Wet Season & Cool, Dry Season & Hot, Humid Season \\
\hline Max. Temp. & $17^{0} \mathrm{C}-44.5^{0} \mathrm{C}$ & $6^{0} \mathrm{C}-42^{\circ} \mathrm{C}$ & $14^{0} \mathrm{C}-49^{0} \mathrm{C}$ \\
\hline Mean & $28.6^{0} \mathrm{C}$ & $25.3^{0} \mathrm{C}$ & $32.7^{0} \mathrm{C}$ \\
\hline SD & $3.2^{0} \mathrm{C}$ & $3.6^{0} \mathrm{C}$ & $4.4^{0} \mathrm{C}$ \\
\hline Min. Temp. & $8^{0} \mathrm{C}-32.5^{0} \mathrm{C}$ & $1{ }^{0} \mathrm{C}-32^{0} \mathrm{C}$ & $6^{0} \mathrm{C}-37^{0} \mathrm{C}$ \\
\hline Mean & $22.2^{0} \mathrm{C}$ & $19.1^{0} \mathrm{C}$ & $21.4^{0} \mathrm{C}$ \\
\hline SD & $2.8^{0} \mathrm{C}$ & $4.2^{0} \mathrm{C}$ & $4.4^{0} \mathrm{C}$ \\
\hline Precipitation & $82.16 \mathrm{~cm}-172.72 \mathrm{~cm}$ & $1.19 \mathrm{~cm}-22.55 \mathrm{~cm}$ & $50.06 \mathrm{~cm}-99.00 \mathrm{~cm}$ \\
\hline Mean & $139.87 \mathrm{~cm}$ & $7.74 \mathrm{~cm}$ & $71.58 \mathrm{~cm}$ \\
\hline SD & $27.55 \mathrm{~cm}$ & $6.76 \mathrm{~cm}$ & $16.12 \mathrm{~cm}$ \\
\hline Months & July-October & November-February & March-June \\
\hline Tiger Sign & $\begin{array}{c}\text { Tiger sign readily obliterated } \\
\text { by rainfall }\end{array}$ & $\begin{array}{c}\text { Highest detection } \\
\text { probabilities }\end{array}$ & $\begin{array}{c}\text { Tigers favour water, limited } \\
\text { sign on land (Choudhury 1999) }\end{array}$ \\
\hline
\end{tabular}

Table 2: List of potential site covariates examined in this study, abbreviations are used in Table 3

\begin{tabular}{|l|l|l|}
\hline Site Covariate & Abbreviation & Description \\
\hline Area & area & Area of beat in hectares \\
\hline $\begin{array}{l}\text { Proportion degraded } \\
\text { habitat }\end{array}$ & degr & $\begin{array}{l}\text { Area in hectares of the beat with a land use category of agricultural land, built-up } \\
\text { land, degraded forest and open forest clubbed together divided by the total area of } \\
\text { the beat. }\end{array}$ \\
\hline Distance from Habitation & hdist & Distance from the edge of the nearest inhabited place to the edge of the beat $(\mathrm{km})$ \\
\hline Total prey & prey & $\begin{array}{l}\text { Sum of observed individuals of tiger prey animals observed in the beat from the } \\
\text { ungulate observation protocol (sambar, chital, wild pig, and barking deer). }\end{array}$ \\
\hline Proportion Dense Forest & dfor & $\begin{array}{l}\text { Area in hectares of the beat with a land use category of dense forest divided by the } \\
\text { total area of the beat. }\end{array}$ \\
\hline Proportion Grassland & grass & $\begin{array}{l}\text { Area in hectares of the beat with a land use category of grassland divided by the total } \\
\text { area of the beat. }\end{array}$ \\
\hline Prey: sambar & sambar & Individuals of sambar observed in the beat from the ungulate observation protocol. \\
\hline Prey: chital & chital & Individuals of chital observed in the beat from the ungulate observation protocol. \\
\hline Prey: wild pig & pig & Individuals of wild pig observed in the beat from the ungulate observation protocol. \\
\hline Prey: barking deer & bdeer & $\begin{array}{l}\text { Individuals of barking deer observed in the beat from the ungulate observation } \\
\text { protocol. }\end{array}$ \\
\hline
\end{tabular}


Swain and Morris
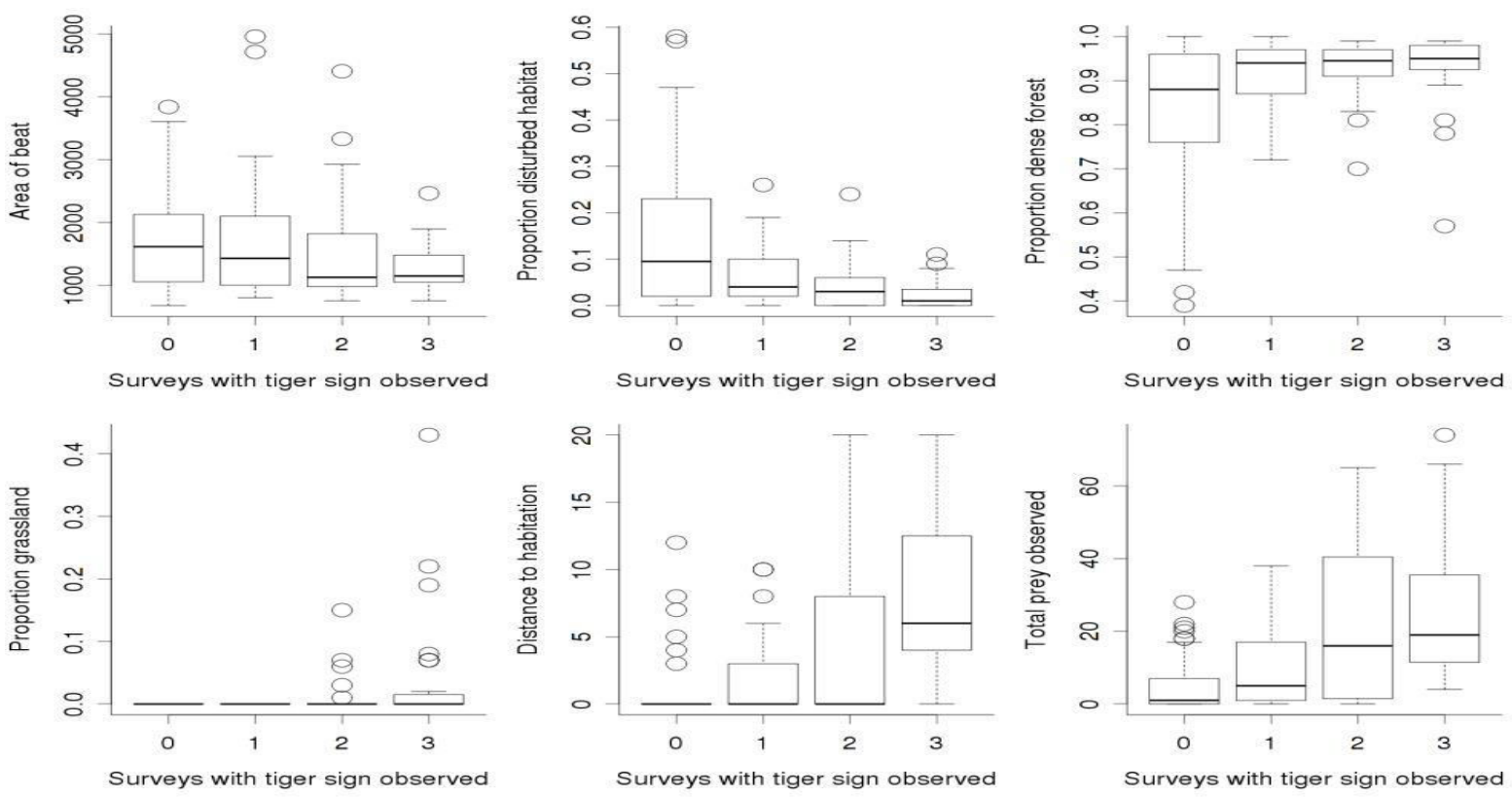

Figure 2: The number of surveys (out of three) in each beat in which tiger sign was observed.
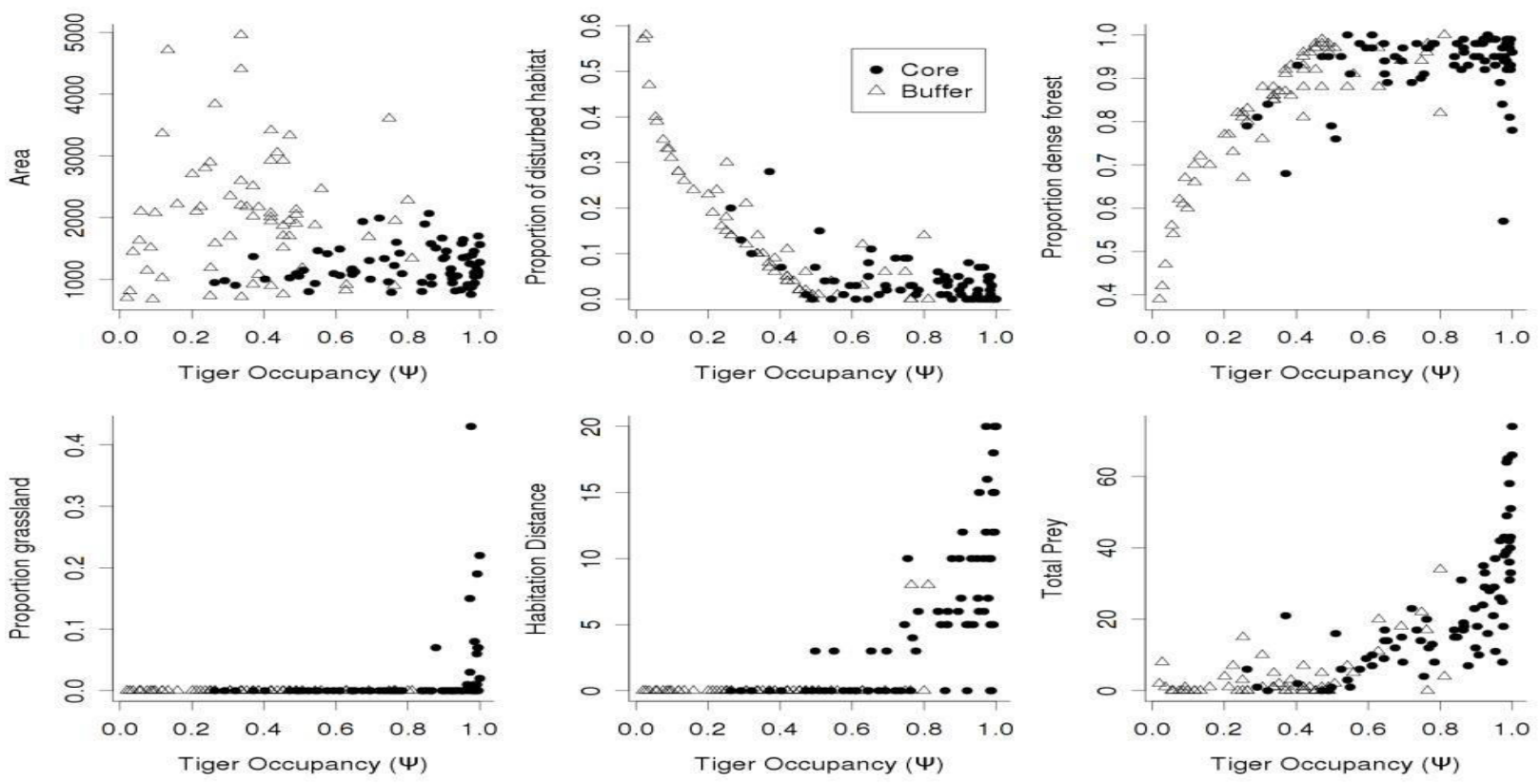

Figure 3: Correlations between site covariates and the tiger occupancy. (Solid circles are beats in the core area, open triangles are beats in the buffer area)

Occupancy Analysis

10. Importantly, area does not correlate with tiger Results of the Occupancy Analysis are shown in occupancy, a concern given the presence of larger Table 3. Three null models (area, constant $\mathrm{p}$, beats in the buffer area. Likewise, models of survey specific $\mathrm{p}$ ) all have $\triangle \mathrm{AIC}$ values larger than constant probability of detection alone (constant $\mathrm{p}$ ) 
and consistent differences between surveys of a site (survey specific $\mathrm{p}$ ) have very low explanatory value. The single best model (the model with the fewest parameters that best explains the data), is $\Psi$ (degr,hdist,prey); occupancy explained by a combination of the proportion of the beat that is composed of degraded habitat, the distance of the beat from human habitation, and the total number of prey animals observed in the beat during the ungulate surveys of that beat (Figure 3). A map of the estimated values of $\Psi$ (degr,hdist,prey) for each beat is shown in Figure 4, the highest tiger occupancy is in the South central core of the reserve.

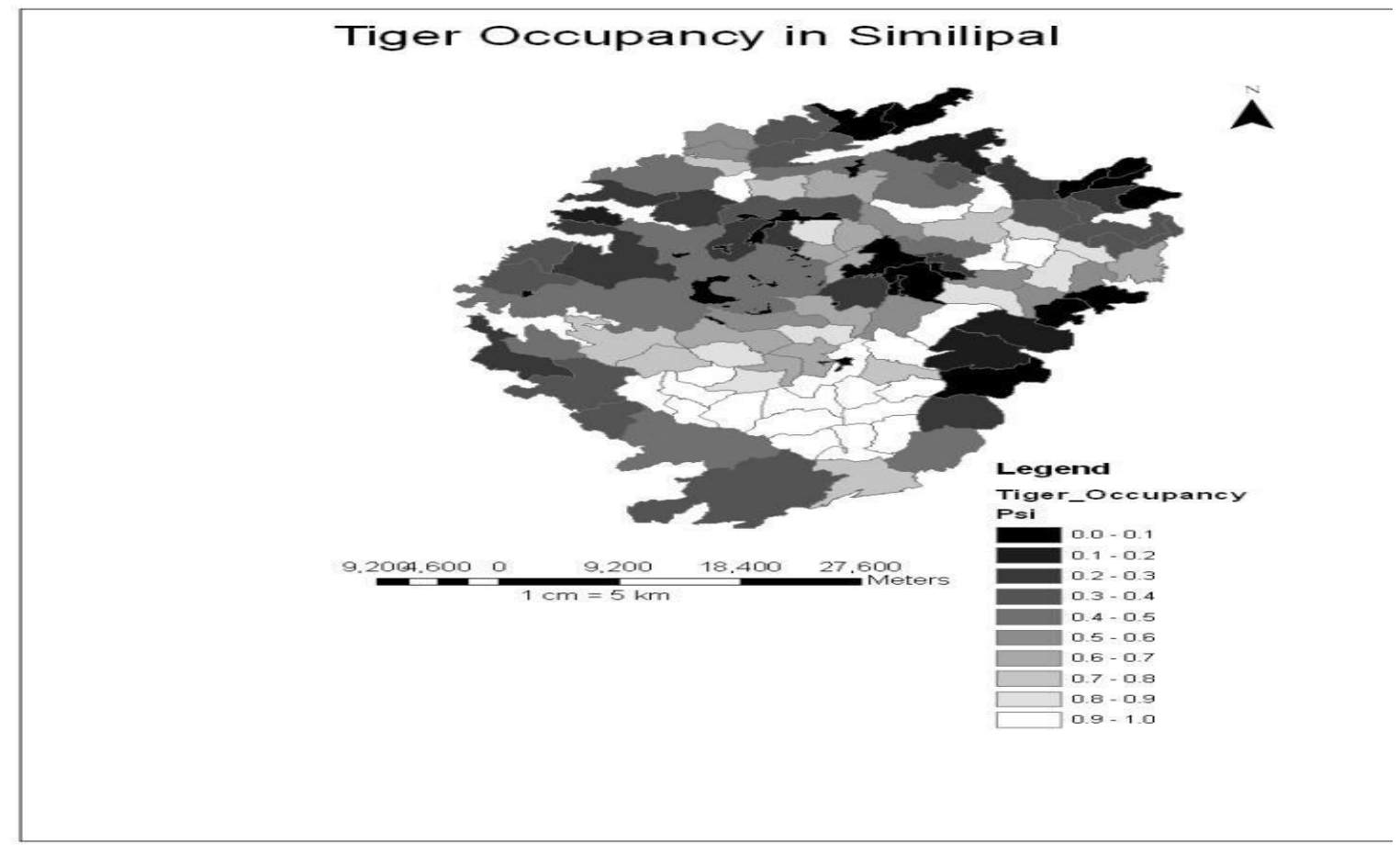

Figure 4: Map of the Similipal Tiger Reserve, India with beats coded for the tiger occupancy for a site as predicted by the $\Psi$ psi(dist,hdist,prey) model.

The models that best explain the data are (1) the combination of proportion of degraded habitat, the distance to habitation, and total prey, (2) the proportion of habitat composed of forest and grassland, along with the total prey, (3) the proportion of degraded habitat and the total prey, and (4) the proportion of degraded habitat, the proportion of forest, the distance to habitation, and the total prey (Table 3). No one model stands out, following Burnham \& Anderson's (2002 p. 184) rule of thumb of AIC weight of $>0.9$ for identification of a single most favorable model, with $\Psi$ (degr,hdist,prey) having an AIC weight of 0.37 . The most important site covariates, that is the most important predictors of tiger occurrence, are the proportion of the beat that has disturbed habitat, the distance of the beat from human habitations, and the total prey observed, with grassland, when present, also being an important predictor. Sampling and Assumptions

Two of the assumptions of the single-species single-season occupancy model of MacKenzie et al. (2006 p.104) are independent of potential covariates. The validity of these assumptions is critical to the applicability of occupancy estimation. These critical assumptions are: (1) Closure that is the occupancy of a site does not change over the course of the sampling. A set of sampling surveys (a "season") provides a snapshot of the population unaffected by birth, death, immigration or emigration, and (2) independence of detection 
Table 3. Summary of models fit to Similipal Tiger Reserve data

\begin{tabular}{|c|c|c|c|c|c|c|c|c|c|c|c|c|}
\hline Model & \#Par & AIC & $\Delta \mathrm{AIC}$ & $\begin{array}{l}\text { AIC } \\
\text { weight }\end{array}$ & $\begin{array}{l}\text { Likeli } \\
\text { hood }\end{array}$ & $-2 \log 1$ & $\begin{array}{l}\operatorname{degr} \\
\beta\end{array}$ & hdist $\beta$ & $\begin{array}{l}\text { dfor } \\
\beta\end{array}$ & $\begin{array}{l}\text { grass } \\
\beta\end{array}$ & $\begin{array}{l}\text { sambar } \\
\beta\end{array}$ & $\begin{array}{l}\text { prey } \\
\beta\end{array}$ \\
\hline$\Psi$ (degr,hdist,prey) & 5 & 433.53 & $0.00 * *$ & 0.3672 & 1.0000 & 423.53 & -0.81 & 0.81 & ---- & --- & --- & 1.17 \\
\hline$\Psi$ (dfor,grass,prey) & 5 & 435.29 & $1.76 * *$ & 0.1523 & 0.4148 & 425.29 & --- & --- & 0.85 & 86.1 & ---- & 1.31 \\
\hline$\Psi$ (degr,prey) & 4 & 435.31 & $1.78 * *$ & 0.1508 & 0.4107 & 427.31 & -0.98 & ---- & ---- & ---- & ---- & 1.52 \\
\hline $\begin{array}{l}\Psi(\text { degr,dfor,hdis,pre } \\
\text { y) }\end{array}$ & 6 & 435.43 & $1.90 * *$ & 0.1420 & 0.3867 & 423.43 & -1.08 & 0.80 & $<\mathrm{SE}$ & ---- & ---- & 1.19 \\
\hline$\Psi($ degr,hdist,sambar & 5 & 437.48 & $3.95 *$ & 0.0783 & 0.2133 & 427.48 & -0.90 & $<\mathrm{SE}$ & ---- & --- & 5.02 & ---- \\
\hline $\begin{array}{l}\Psi(\text { degr,dfor,gras,pre } \\
\text { y) }\end{array}$ & 6 & 436.62 & $3.09 *$ & 0.5100 & 0.1388 & 424.62 & $<\mathrm{SE}$ & ---- & $<\mathrm{SE}$ & 84.7 & ---- & 1.37 \\
\hline$\Psi($ all $)$ & 8 & 437.60 & $4.07 *$ & 0.4800 & 0.1307 & 421.60 & $<\mathrm{SE}$ & 0.72 & $<\mathrm{SE}$ & 80.2 & --- & 1.29 \\
\hline$\Psi$ (hdist,prey) & 4 & 440.96 & $7.43 *$ & 0.0089 & 0.0244 & 432.96 & ---- & 1.13 & ---- & ---- & ---- & 1.24 \\
\hline$\Psi($ sambar $)$ & 3 & 445.58 & 12.05 & 0.0009 & 0.0024 & 439.58 & --- & ---- & ---- & ---- & 119 & ---- \\
\hline$\Psi$ (prey) & 3 & 447.30 & 13.74 & 0.0004 & 0.0010 & 441.30 & ---- & ---- & ---- & ---- & ---- & 1.80 \\
\hline$\Psi($ deg,dfor,grass) & 5 & 450.39 & 16.88 & 0.0001 & 0.0002 & 440.39 & $<\mathrm{SE}$ & --- & $<\mathrm{SE}$ & 93.4 & ---- & ---- \\
\hline$\Psi$ (hdist) & 3 & 451.31 & 17.76 & 0.0001 & 0.0001 & 445.31 & --- & 2.06 & ---- & ---- & ---- & ---- \\
\hline$\Psi($ degr $)$ & 3 & 455.53 & 22.00 & 0.0000 & 0.0000 & 449.53 & -1.33 & ---- & ---- & ---- & ---- & ---- \\
\hline$\Psi($ pig $)$ & 3 & 457.7 & 24.17 & 0.0000 & 0.0000 & 451.70 & & & & & & \\
\hline$\Psi($ bdeer $)$ & 3 & 472.18 & 38.65 & 0.0000 & 0.0000 & 466.18 & & & & & & \\
\hline$\Psi($ cheetal $)$ & 3 & 482.18 & 48.56 & 0.0000 & 0.0000 & 476.18 & & & & & & \\
\hline$\Psi($ area $)$ & 3 & 482.89 & 49.33 & 0.0000 & 0.0000 & 476.89 & & & & & & \\
\hline Constant $\mathrm{p}$ & 2 & 483.45 & 49.89 & 0.0000 & 0.0000 & 479.45 & & & & & & \\
\hline Survey-Specific $p$ & 4 & 484.05 & 50.49 & 0.0000 & 0.0000 & 476.05 & & & & & & \\
\hline$\Psi$, theta(t),p(.) & 3 & 485.45 & 51.98 & 0.0000 & 0.0000 & 479.45 & & & & & & \\
\hline
\end{tabular}

$\triangle$ AIC is the difference between the AIC of a model and the AIC of the most parsimonious model,

** marks models with substantial support having a $\Delta$ AIC of less than 2 , * models having some support with a $\Delta$ AIC of less than 10 .

Untransformed estimates of some covariates are listed in the last three columns.

Untransformed estimates of $\beta$, coefficients for covariates in models with a $\triangle \mathrm{AIC}$ from the most parsimonious model of less than 10 .

Only values of $\beta$ that are larger than the standard error are reported here.

"-.--" indicates that a covariate is not present in a model,

" $<\mathrm{SE}$ " indicates that the $\beta$ value for that covariate was less than the standard error.

history of a species at a site, that is one survey of a the detection probability for subsequent site does not alter the occupancy probability or applications of that sensor. For tigers, three detection probability for a species in a subsequent repeated surveys of the same transect would be survey at a site (along with independence of likely to violate the assumption of independent detection from site to site, a survey at one site detection history. The presence of human scent and doesn't alter the detection probability at another disturbance from a survey would be likely to deter site).In more general terms, the application of a tigers from approaching that transect, reducing sensor to detect the target species should not affect detection probabilities on subsequent resurveys of 
that same transect. Thus, it is important that the three tiger surveys of each beat in this study were on distinct transects within the beat rather than repeated visits to the same transect over three days. These two critical assumptions need to be correct in order for the method of occupancy modeling to produce valid results. Two other key assumptions of single-species single-season models involve covariates, and can be evaluated by the comparison of different models. These are: (3) that either occupancy probability is constant or the differences in occupancy probabilities are effectively modeled with covariates, and (4) that either detection probability is constant or that detection probability is effectively modeled with covariates. Another assumption of occupancy analysis is that there is no substantive unmodeled heterogeneity in detection probabilities. All of these assumptions can be assessed from the analysis. The sampling units of this study (the beats) are effectively arbitrary spatial units, although beat boundaries often do follow linear natural features such as ridge lines or drainages. Area of beats vary (from $6.80 \mathrm{~km}^{2}$ to $49.6 \mathrm{~km}^{2}$, mean $15.9 \mathrm{~km}^{2}$ ), with about half the beats in the buffer area being larger than the largest beat in the core area. Core area beats have a median area of $11.3 \mathrm{~km}^{2}$ with first and third quartiles at 10.0 and $13.8 \mathrm{~km}^{2}$ in contrast to the buffer beats, which have a median area of $19.8 \mathrm{~km}^{2}$ and first and third quartiles of 13.0 and $24.8 \mathrm{~km}^{2}$. Given the large $\triangle \mathrm{AIC}$ value for area, the area of beats does not appear to explain the tiger occupancy patterns.

\section{Management Implications}

A naive conclusion from the observation that distance to habitation correlates with tiger occupancy would be that removing villages from the reserve would increase tiger occupancy. Closer examination of the data, however, leads to much more nuanced conclusions, particularly from the observation that both beat 51, Jenabil, compartment KH-26, and beat 40, Balikhal, compartment P-10 are adjacent to habitation, but both had tiger sign observed on two of three surveys and both have predicted $\Psi$ values of about 0.98 . These outliers indicate that human habitation in the reserve can be consistent with high tiger occupancy. Indeed 5 beats with a distance to habitation of zero have predicted $\Psi$ values greater than 0.80 , and predicted $\Psi$ values for beats adjacent to villages span the range from 0 to 0.98 . Distance to habitation alone is a poor predictor of tiger occupancy. Examination of the relationships amongst tiger occupancy, proportion of each beat with disturbed habitat and the number of total prey leads to the conclusions that the proportion of disturbed habitat is a good predictor for the tiger occupancy of a beat only for tiger occupancies below about 0.50 (or when the proportion of disturbed habitat is above about $15 \%$ ), and that the abundance of prey animals is a good predictor of tiger occupancy for tiger occupancies above 0.50 , and a poor predictor below that. This observation has clear management implications, first, for areas with low psi, reduce amount of disturbed habitat to below $10 \%$ of total area. Second, for areas with moderate $\Psi$, increase prey animal abundance, which suggests an increased focus on enforcement against poaching on prey animals. Abundance of prey is a well known determinant of tiger population size (e.g. Miquelle et al., 1999; Karanth and Stith, 1999).

The results of the occupancy analysis leads us to divide the beats into four categories, each with its own management strategy: (1) Beats of greatest concern, with psi $<0.10$, need extensive remediation of multiple problems. (2) Beats for targeted reduction of habitat disturbance (e.g. reduction of tree felling, reduction of grazing, reduction of human activity, increase of canopy cover). For these beats, we propose a target of reduction of the proportion of disturbed habitat for each beat to less than $10 \%$ of the area of the beat. The proportion of beat area coded as disturbed habitat for these beats ranges from just over $10 \%$ to about $30 \%$. (3) Beats for targeted reduction of human effects on prey population: These beats show lower availability of prey animals and a relatively small proportion (less than about $15 \%$ ) of degraded habitat. Target for these beats is increase of the populations of tiger prey species, through reduction of hunting of these prey species, such as through increased enforcement to prevent poaching on prey species. Miquelle et al. (2009), recommend a management technique for increasing prey populations: "give local people an incentive to support higher populations of key prey species". Participatory wildlife management may be introduced, by motivating residents of buffer villages to protect prey species, and in return allowing collection of non-timber forest produce 
(NTFP) from the buffer. (4) The remainder of the beats in the reserve have a high tiger occupancy and the least human disturbance. The strategy for these remaining beats is maintenance of current management procedures, including patrols and deployment of local youth as green brigades, a concept introduced in Similipal with great success particularly during the season of community hunting by indigenous people. Figure 5 illustrates these management implications.

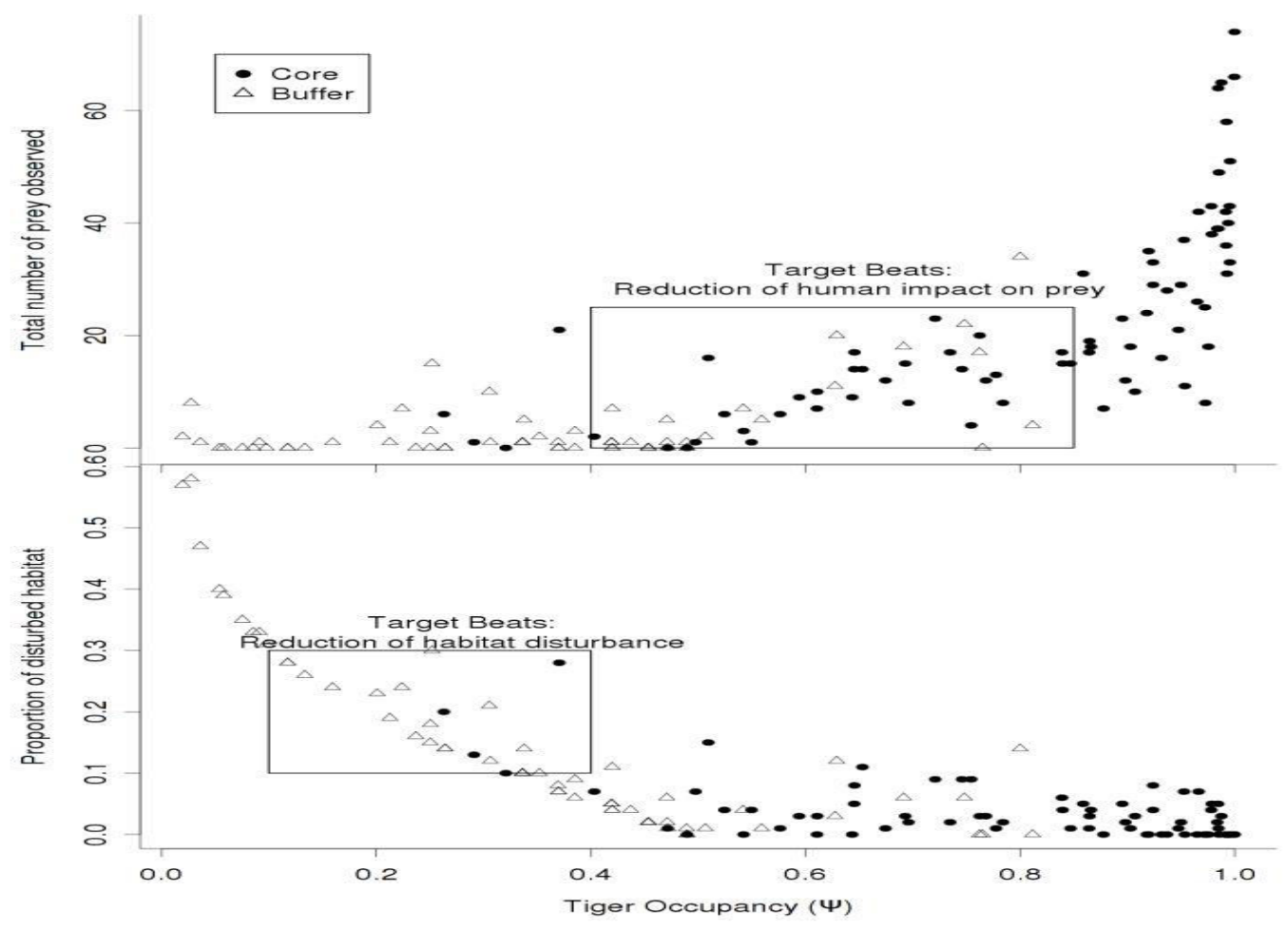

Figure 5: Management implications of tiger occupancy analysis in Similipal Tiger Reserve, India.

\section{Continued Monitoring}

This study provides only a baseline from which future monitoring can determine the effectiveness of management actions in maintaining tiger populations in the reserve. The procedure discussed here in is simple, cost effective, and engages both staff and local populace in monitoring conditions of the reserve. A beat forest guard, and for that matter a member from the local community, who participates in search of signs of carnivores and direct sighting of ungulates can easily observe during a survey the impacts of management strategy undertaken in the beat. The simplicity of the procedure comes from its reliance on only the monitoring staff collecting some basic observational data in the course of their patrols. As it is cost effective, it can be repeated every year and this process of monitoring is participatory (Evans \& Guariguata 2008) as it involves ground level staff and the local communities. We will note that to reduce the potential bias introduced by the larger areas in the buffer region, subdivision of each of the largest beats into two samples in the next round of sampling would be advisable, with 3 transect surveys for sign made in each half.

\section{Conclusion}

Tigers are a highly endangered species. The threats to the surviving populations produce a very strong need to obtain tightly temporally spaced monitoring data in order to rapidly react to declines in populations. Monitoring needs to be simple and effective in the field with clear implications for management. Occupancy analysis of sign survey data is a simple and low cost monitoring method. 
With repeated surveys building up a time series, it is able to identify both declines and potential causes for the declines. In line with other workers (e.g., MacKenzie et al, 2005), we find occupancy analysis of cryptic carnivore sign survey data highly suitable for complex forested terrain such as that of Similipal. The sign survey method depends on substantial numbers of trained and experienced staff. It has a caveat that sampling protocols and procedures need to be well designed. Sign surveys have a very great advantage of low cost and low requirements for technical infrastructure, allowing them to be repeated frequently to build up robust time series of monitoring data for better understanding the impacts of management actions on the monitored populations. Sign surveys have important side consequences and correlates, including capacity building of staff, improving their day to day monitoring abilities and their abilities to recognize short term changes in their field area.

Sign surveys are also highly suitable for engagement of local populations in monitoring and conservation efforts. Similipal tiger reserve, by its size and qualities, is one of the most important tiger reserves in the Indian subcontinent, with an identified minimum population target of 219 tigers (Ranganathan, et al., 2008, p. 70). In a single season occupancy analysis of tiger sign survey data from Similipal reserve, we have identified habitat disturbance as an important correlate of low tiger occupancy, and tiger prey species abundance as an important correlate of occupancy in areas where habitat disturbance is low. This analysis has direct management implications, particularly reducing the proportion of habitat disturbance and human impact on the reserve in areas with more than $10 \%$ habitat disturbance, and increasing prey abundance in areas of lower habitat disturbance. Analysis will help identify which villages need to be prioritized for relocation by identifying those with greatest impact on habitat degradation and prey populations. We recommend regular repeated sign surveys in the future, along with cross correlation with other monitoring data for standardization, particularly camera trap capture/recapture studies.

\section{Acknowledgements}

We would like to acknowledge the support of the Harvard Forest through a Bullard Fellowship to D.
S. We also acknowledge the contribution of $\mathrm{J}$. McLaren in analyzing the weather data. This manuscript has benefited from comments by S. F. Morris and J. A. Royle.

\section{References}

Burnham, K.P., and Anderson, D.R. 2002. 'Model selection and multimodel inference' [ $2^{\text {nd }}$ ed.]. (Springer-Verlag: New York).

Choudhury, S.R. 1999. 'Khairi: The beloved tigress'. (Natraj Publishers: Dehradun, India).

Dinerstein, E., Loucks, C., Wikramanayake, E., Ginsberg, J., Sanderson, E., Seidensticker, J., Forrest, J., Bryja, G., Heydlauff, A., Klenzendorf, S., Leimgruber, P., Mills, J., O'Brien, G.T., Shrestha, M., Simons, R., and Songer, M. 2007. The fate of wild tigers. BioScience, 57, 508-14.

Evans, K., and Guariguata, M.R. 2008. 'Participatory monitoring in tropical forest management: A review of tools, concepts and lessons learned'. (Center for International Forestry Research (CIFOR): Bogor, Indonesia).

Gittleman, J.L. 1985. Carnivore body size: Ecological and taxonomic correlates. Oecologia 67, 540-554.

Graham, K., Beckermaman, A.P., and Thirgood, S. 2005. Human-predator-prey conflicts: Ecological correlates, prey losses and pattern of management. Biological Conservation 122, 159-171.

Hines, J.E. 2006. 'PRESENCE2- Software to estimate patch occupancy and related parameters'. USGS-PWRC. [Software] http://www.mbrpwrc.usgs.gov/software/presence.html.

Jhala, Y., Qureshi, Q., and Gopal, R. 2005. Field guide: Monitoring tigers, co-predators, prey and their habitats. (Project Tiger, Union Ministry of Environment and Forests: New Delhi, India).

Johnsingh, A.T., and Negi, A.S. 2003. Status of tiger and leopard in Rajaji-Corbett Conservation Unit, northern India. Biological Conservation 111, 385-393.

Karanth, K.U., Nichols, J.D. \& Sen, P.K., and Rishi, V. 2002. Monitoring tigers and prey: conservation needs and managerial constraints. In 'Monitoring tigers and their prey: A manual for researchers, managers and conservationists in tropical Asia'. (Eds. Karanth, K.U., and Nichols J.D.) pp. 1-8. (Centre for Wildlife Studies: Bangalore, India).

Karanth, K.U., and Stith, B.M. 1999. Prey depletion as a critical determinant of tiger population viability. In 'Riding the Tiger: Tiger conservation in human-dominated landscapes'. (Eds. Seidensticker, J.S., Christie, S., and 


\section{Swain and Morris}

Jackson, P.) pp. 100-113. (Cambridge University Press: London).

Karanth, K.U., Nichols, J.D., Seidensticker, J., Dinerstein, E., Smith, J.L.D., McDougal, C., Johnsingh, A.J.T., Chundawat, R.S., and Thapar, V. 2003. Science deficiency in conservation practice: The monitoring of tiger populations in India. Animal Conservation 6,141-146.

Kitchener, A.C. 1999. Tiger distribution, phenotypic variation and conservation issues. In 'Riding the Tiger: Tiger conservation in human-dominated landscapes' (Eds. Seidensticker, J.S., Christie, S., and Jackson, P.) pp. 19-39. (Cambridge University Press: London).

Mackenzie, D.I., Nichols, J.D., Lachman, G.B., Droege, S., Royale, J.A., and Langtimm C.A. 2002. Estimating site occupancy rates when detection probability is less than one. Ecology 83,2248-2255.

MacKenzie, D.I., Nichols, J.D., Royle, J.A., Pollock, K.H., Bailey, L.L., and Hines, J.E. 2006. 'Occupancy estimation and modeling: Inferring patterns and dynamics of species occurrence'. (Academic Press: Burlington, MA).

Maza'k, V.J. 1996. 'Der tiger'(Reprint of 1983 edn.). (Magdeburg: Westarp Wissenschaften).

Miquelle, D.G., Smirnov, E.N., Merrill, T.W., Myslenkof, A.E., Quigley, H.B., Hornocker, M.C., and Schleyer, B. 1999. Heirarchical Spatial Analysis of Amur tiger relationships to habitat and prey. In 'Riding the Tiger: Tiger conservation in human-dominated landscapes' (Eds. Seidensticker, J.S., Christie, S., and Jackson, P.) pp. 71-99. (Cambridge University Press: London).

Nichols, J.D. 1991. Extensive monitoring programs viewed as long-term population studies: The case of North American waterfowl. Ibis 133(supplement 1), 89-98.

Nichols, J.D., and Karanth, K.U. 2002. Population monitoring: A conceptual framework. In 'Monitoring tigers and their prey: A manual for researchers, managers and conservationists in tropical Asia'. (Eds. Karanth, K.U., and Nichols J.D.) pp. 23-28. (Centre for Wildlife Studies: Bangalore, India).
Nowell, K., and Jackson, P. 1996. 'Wild cats: Status survey and conservation action plan'. (IUCN: Gland, Switzerland).

Ramakrishnan, U., Coss, R.G., and Pelkey, N.W. 1999. Tiger decline caused by the reduction of large ungulate prey: Evidence from a study of leopard diets in southern India. Biological Conservation 89,113-120.

Ranganathan, J., Chan, K.M.A., Karanth, K.U., and Smith, J.L.D. 2008. Where can tigers persist in future? A landscape-scale, density-based population model for the Indian subcontinent. Biological Conservation 141, 67-77.

Seidensticker, J., Christie, S., and Jackson, P. (eds) 1999. 'Riding the Tiger: Tiger conservation in human-dominated landscapes'. (Cambridge University Press: London).

Singh, L.A.K. 1999. 'Tracking tigers: Guidelines for estimating wild tiger populations using the pugmark technique'. (WWF Tiger Conservation Program: New Delhi, India).

Sunquist, M., Karanth, K.U., and Sunquist, F. 1999. Ecology, behavior and resilience of the tiger and its conservation needs. In 'Riding the Tiger: Tiger conservation in humandominated landscapes' (Eds. Seidensticker, J.S., Christie, S., and Jackson, P.) pp. 5-18. (Cambridge University Press: London)

Swain, D. 2005. Similipal biosphere reserve. In 'Proceedings of Indo-US workshop on conservation of biodiversity in Similipal biosphere reserve (14-15 November, 2005)'. pp. 38-41. (North Orissa University: Baripada, India).

Wang, S.W., and Macdonald, D.W. 2006. Livestock predation by carnivores in Jigme Singye Wangchuck National Park, Bhutan. Biological Conservation 129, 558-565.

Wilson, D.E., and Reeder D.M. (eds) 2005. 'Mammal Species of the World. A Taxonomic and Geographic Reference' (3rd ed). Johns Hopkins University Press. Available at http://www.press.jhu.edu. 
A list of beats with targeted management strategies

\section{Supporting Information}

\begin{tabular}{|c|c|c|c|}
\hline Highest Concern & Reduce Disturbance & Increase Prey Protection & Maintain Present Protection \\
\hline $\begin{array}{l}\text { Haldibani BLE-12(P2) } \\
\text { Kontasole BLE-11(P1) } \\
\text { Bahalda SJ-6 } \\
\text { Phulabadia ED-3,8 } \\
\text { Kanchhinda BLW-3,4 } \\
\text { Balidiha P-5 } \\
\text { Sapanchua SJ-5 } \\
\text { Gendapokhari BLE-12(P1) }\end{array}$ & $\begin{array}{l}\text { Ghatakuanri BLW-1,2 } \\
\text { Chadheipahadi BH-12 } \\
\text { Nuagaon SJ-11,12,10,9(P2) } \\
\text { Dengam SJ-16,18,17(P1),ED-4 } \\
\text { Rangamatia BLE-1,BLE-2 } \\
\text { Uski BH-9,10,15 } \\
\text { Bisipur TL-1,2 } \\
\text { Badgaon BLE-10,BLE-11(P2) } \\
\text { Tulasibani BH-1,2,3 } \\
\text { Kaliani KH-1,2 } \\
\text { Dhudruchampa BLE-20 } \\
\text { Champagarh P-4 } \\
\text { Garsimilipal BLW-17,BLW-16(P2) } \\
\text { Taldiha ED-7(P2),12,13,14,11(P2) } \\
\text { Jamuani BH-4,8 } \\
\text { Pithabata-II P-9 } \\
\text { Ektali KH-5 } \\
\text { Kiajhari WD-1,2,3 } \\
\text { Namti-I P-2 } \\
\text { Jaldiha BLE-5,BLE-3 } \\
\text { Dangadiha-II SL-8,9,13,15 } \\
\text { Kendumundi TL-4,3 } \\
\text { Dangadiha-I SL-16,17,10,18,SL- } \\
\text { 11(P2),SL-6(P2) } \\
\text { Pithabata P-3 } \\
\text { Barehipani BH-5,6,7 } \\
\text { Talabandha BLW-5,6,7 } \\
\text { Mituani SL-3 } \\
\text { Badmahuldiha TL-5,6 } \\
\text { Digdiga P-13,SJ-1 } \\
\text { Khejuri KH-13 } \\
\text { Asadola KD-3,4 }\end{array}$ & $\begin{array}{l}\text { Nigirdha BLE-19 } \\
\text { Fulbaria BH-16,18 } \\
\text { Charabandha BLW-8,9,10 } \\
\text { Gurguria KH-3,10 } \\
\text { Kuanribil KH-4,11,12 } \\
\text { Dudhiani WD-7,9 } \\
\text { Baghalata WD-10 } \\
\text { Utras KH-6,7,8 } \\
\text { Khaparkhai TL-7 } \\
\text { Ranipat WD-4 } \\
\text { Badkhamana TK-8,9 } \\
\text { Purunapani SL-4,5,7 } \\
\text { Barakamuda WD-5,6 } \\
\text { Sanasialinai KD-8,9 } \\
\text { Badbaliposi TL-8,9,10 } \\
\text { Barigaon KH-9,15,16 } \\
\text { Chakidi-I BLE-4 } \\
\text { Hatibadi WD-11,12 } \\
\text { Pithabata-I P-8 } \\
\text { Mohanpur BH-13,14 } \\
\text { Tamalabandha KD-6,10 } \\
\text { Chakidi-II BLE-6 } \\
\text { Chandanchaturi SJ-4 } \\
\text { Bhatunia BLW-13 } \\
\text { Dhudruchampa BLE-23 } \\
\text { Anantapur TK-6,TK-5(P1) } \\
\text { Khejuri KH-19 } \\
\text { Joranda BLE-16,BLE-17 } \\
\text { Bankidihi KD-1,2,5 } \\
\text { Gopinathpur P-14 } \\
\text { Badamakabadi-I P-19 } \\
\text { Kabatghai-II KH-18 } \\
\text { Bakua-I KH-14 } \\
\text { Nawana BH-17 } \\
\text { GarSimilipal BLW-16(P1) } \\
\text { Kabatghai-I KH-17 } \\
\text { Karkachia BLW-12 } \\
\text { Hatighar-II KH-25 } \\
\text { Nuagaon KH-24 } \\
\text { Chandanchaturi SJ-2,SJ-3 } \\
\text { Champajhar SL-14,12 } \\
\text { Matighati BLW-15 } \\
\text { Andharituta-II P-16 } \\
\text { Rajabasa BLE-21,22 } \\
\text { Bhundadar P-6(P1)(P2) } \\
\text { Hatighar-I KH-23(P1),(P2) } \\
\text { Budhigaon WD-8,13,14,16 } \\
\text { Mahavirsal-I WD-15 } \\
\text { Allapani KD-7 } \\
\text { Bakua-II BLW-18 } \\
\text { Edelbeda WD-19,17(P2) } \\
\text { Hatisal-I ED-1,2 } \\
\text { Kairakacha BLW-11 } \\
\text { Pandabandha BLE-18 } \\
\text { Podadiha TK-10,11,TK-7(P2) } \\
\text { Mandaljhari SL-1,2 } \\
\text { Andharituta-I P-15 } \\
\text { Namti-II P-7 } \\
\text { Badamakabadi-II P-17,18 }\end{array}$ & $\begin{array}{l}\text { Barehipani BH-11,BLW14 } \\
\text { Chhatadanda BLW-19,BLE-24 } \\
\text { Gurandia-I KH-21 } \\
\text { Palasibeda P-12 } \\
\text { Devasthali-II WD-22,25 } \\
\text { Ranasa KH-22 } \\
\text { Mahavirsal-II WD-18 } \\
\text { Baunskhal BLE-8,9 } \\
\text { Kachudahan P-11 } \\
\text { Gurandia-II KH-20 } \\
\text { Jamunagarh KH-27 } \\
\text { Jodapal-I SJ-7 } \\
\text { Sunpokhari-I SJ-13 } \\
\text { Gunduria TK-1 } \\
\text { Bhajam P-1 } \\
\text { Jodapal-II SJ-14 } \\
\text { Khadkei BLE-14,BLE-15 } \\
\text { Dhundubasa SJ-8,9(P1) } \\
\text { Dhobighat TK-2,SL-6(P1) } \\
\text { Bhanjabasa TK-4,TK-5(P2),TK- } \\
\text { 7(P1) } \\
\text { Kusumbani BLE-13 } \\
\text { Kandadhanu WD- } \\
\text { 17(P1),20(P1),20(P2) } \\
\text { Bengapani WD-30 } \\
\text { Patbil WD-24 } \\
\text { Baunskhal BLE-7 } \\
\text { Sarua ED-6,ED-7(P1) } \\
\text { Hatisal-II ED-5,ED-9 } \\
\text { Jenabil KH-26 } \\
\text { Sunpokhari-II SJ-15,17(P2) } \\
\text { Tarinibilla WD-29 } \\
\text { Balikhal P-10 } \\
\text { Pokharibadi WD-23 } \\
\text { Meghasini WD-32 } \\
\text { Chahala KD-11 } \\
\text { Devasthali-I WD-21 } \\
\\
\text { UBK WD-28 } \\
\text { Bahaghar WD-26 } \\
\text { Matughar WD-31 } \\
\text { Tiktali ED-10,ED-11(P1) } \\
\text { Tinadiha WD-27 } \\
\text { Balidar TK-3,SL-11(P1) }\end{array}$ \\
\hline
\end{tabular}

